\title{
Assessment of Patients Having Oral Cancer Without Habits
}

\section{Keerthana Baskar ${ }^{1}$, Mahathi Nerella ${ }^{2}$, Sreedevi Dharman ${ }^{3}$}

\begin{abstract}
'Saveetha Dental College and Hospitals, Saveetha Institute of Medical and Technical Sciences, Saveetha University, Chennai, India; ${ }^{2}$ Reader, Department of Oral and Maxillofacial Surgery, Saveetha Dental College and Hospitals, Saveetha Institute of Medical and Technical Sciences, Saveetha University, Chennai, India; ${ }^{3 R e a d e r, ~ D e p a r t m e n t ~ o f ~ O r a l ~ m e d i c i n e ~ a n d ~ R a d i o l o g y, ~ S a v e e t h a ~ D e n t a l ~ C o l l e g e ~ a n d ~ H o s p i t a l s, ~ S a v e e t h a ~}$ Institute of Medical and Technical Sciences, Saveetha University, Chennai, India.
\end{abstract}

\section{ABSTRACT}

Background: Cancer is the most prevalent disease in today's world with oral cancer being the sixth most malignant disease in the world.

Objective: The study aims at assessing the occurrence of oral cancer in patients without any habits.

Methods: The study was done in a university set up in a Private Dental College, Chennai. This study was done retrospectively by analyzing case records of patients who reported between the months of June 2019 to March 2020. Simple random sampling was done to minimize sampling bias. Case sheets were filtered based on the data required. The final sample size was 50 patients with oral cancer. The data pertaining to the habits of the patient was collected.

Results: It was observed that about $8 \%$ of the patients without any oral habits were seen to have oral cancer. Females suffering from oral cancer, predominantly had no associated oral habits.

Conclusion: Within the limits of the study, it was found that patients having oral cancer with no adverse oral habits were significantly less. Female patients having oral cancer with no adverse habits was comparatively more than male patients.

Key Words: Diet, Habits, HPV Virus, Oral cancer, Prevalence, Smoking

\section{INTRODUCTION}

One of the most common malignancies in the world is oral cancer. It is more common in South East Asia due to the prevalence of oral habits such as betel nut chewing, smoking, alcohol consumption. Apart from these factors, there are other various etiological factors that cause oral cancer. ${ }^{1}$ The two main factors which influence cancer are genetic and epigenetic. The incidence of oral cancer in young adults ranges from $0.4 \%$ to $5.5 \%$. The absence of significant habits has led many people to consider other factors such as diet, immune deficiency, genetic factors, certain viruses such as herpes simplex virus, human papillomavirus in the etiopathogenesis of oral cancer. ${ }^{2,3}$

It has also been cited in earlier literature that oral cancer develops sometimes with no associated risk factors. ${ }^{4}$ Genetic predisposition has been shown to be an etiological factor for OSCC. In a study done by Cooper et al., 31 of 105 Head and neck cancer patients had relatives that developed oral can- cer. $^{5}$ It is believed that certain individuals inherit the susceptibility to metabolize carcinogens and pro-carcinogens and have impaired ability to repair DNA damage. ${ }^{6}$

The use of mouthwash is also known to have been an etiological factor as they usually contain alcohol as a solvent or as preservative. ${ }^{7}$ Viral infections caused by EBV, HPV, and herpes simplex virus are considered an important etiological factor. Oral hairy leukoplakia and lymphoproliferative disease in immunosuppressed patients is caused by EBV. HPVs are the most common group of viruses implicated in oral carcinogenesis. These cause benign proliferative lesions such as papillomas, condyloma accuminatum, verruca vulgaris, and Heck's disease. HPV, most commonly found in genital cancers has also been found commonly in oral cancers. ${ }^{8,9}$ Fungal infections such as those caused by Candida species, most importantly, Candida albicans has been implicated in the pathogenesis of oral premalignant lesions. Various clinical trials, surveys, and reviews have been carried out by our team. Now, we are focusing on epidemiological studies. The

\section{Corresponding Author:}

Mahathi Nerella, Reader, Department of Oral and Maxillofacial Surgery, Saveetha Dental College, Saveetha Institute of Medical and Technical Sciences, Saveetha University, Chennai, India; Ph: 9840958142; Email: mahathin.sdc@saveetha.com

ISSN: 2231-2196 (Print)

Received: 07.09.2020
ISSN: 0975-5241 (Online)

Revised: 06.10 .2020
Accepted: 04.11 .2020
Published: 26.12 .2020 
purpose of this study is to assess the occurrence of oral cancer in patients without any habits.

\section{MATERIALS AND METHODS}

\section{Study Setting}

This retrospective study was based on data collected from the patient records of a Private Dental College and Hospitals. Records of patients who reported between the months of June 2019 to March 2020 were reviewed. Approval was obtained from the Institutional Scientific Review Board. Two examiners were included in the study. The ethical approval number for the study is SDC/SIHEC/2020/DIASDATA/0619-0320.

\section{Sampling}

Cross verification of data for error was done by additional reviewers and by photographic evaluation. Simple random sampling was done to minimize sampling bias. After reviewing, the case sheets were filtered based on data required. The final sample size was 50 patients with oral cancer. The inclusion criteria were patients with oral cancer. The exclusion criteria were patients without oral cancer, patients with premalignant conditions, and patients whose case records were incomplete.

\section{Data collection}

The data was entered in the system in a methodical manner. The data was entered in excel manually and imported to SPSS for analysis.

\section{Analytics}

IBM SPSS Software [Version 19: IBM corporation NY USA] was used for data analysis. Descriptive statistics which included frequency of distribution was used for the statistical analysis. The independent variables were age and gender. Chi-square test was performed. The level of significance was set at 0.05 .

\section{RESULTS AND DISCUSSION}

The data was imported to SPSS version 19 and the results were obtained using Chi-square test. In this study, it was found that about $8 \%$ of the patients had oral cancer without any association with adverse oral habits (Figure 1). The habits that were present were smoking, gutka consumption, and paan chewing. It was also found that oral cancer in patients not having any habits was predominant in females, which accounted for $6 \%$ of cases. The occurrence of oral cancer in male patients without any habits was found to be $2 \%$. (Figure 2).

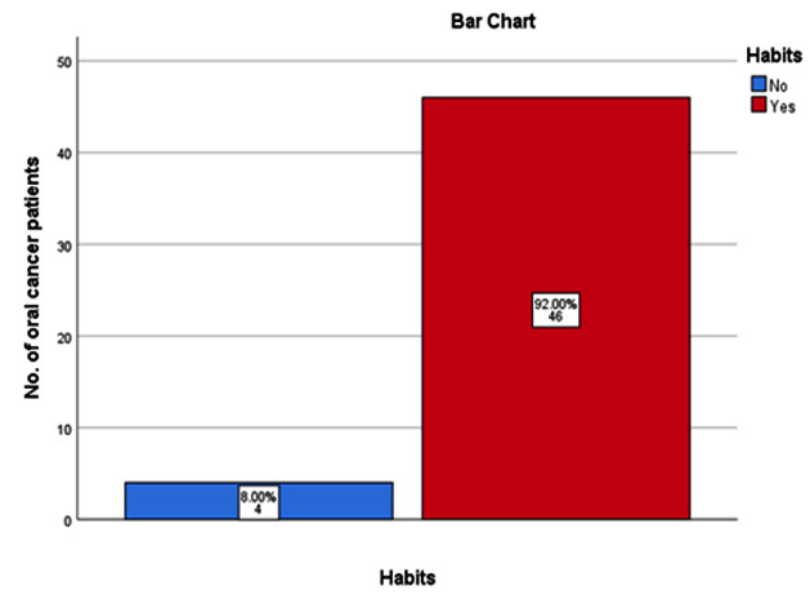

Figure 1: This is a bar graph showing the association between oral cancer and the presence or absence of habits. The $X$-axis denotes the presence or absence of habits and Y-axis denotes the number of patients with oral cancer. The majority of oral cancer patients were found to have adverse oral habits (red) when compared to patients without adverse oral habits (blue). A Chi-square test was done and the association was found to be statistically significant. Pearson's Chi-square value: 52.000 , df: 2, p-value: $0.000(<0.05)$. There is a significant association between habits and the occurrence of cancer.

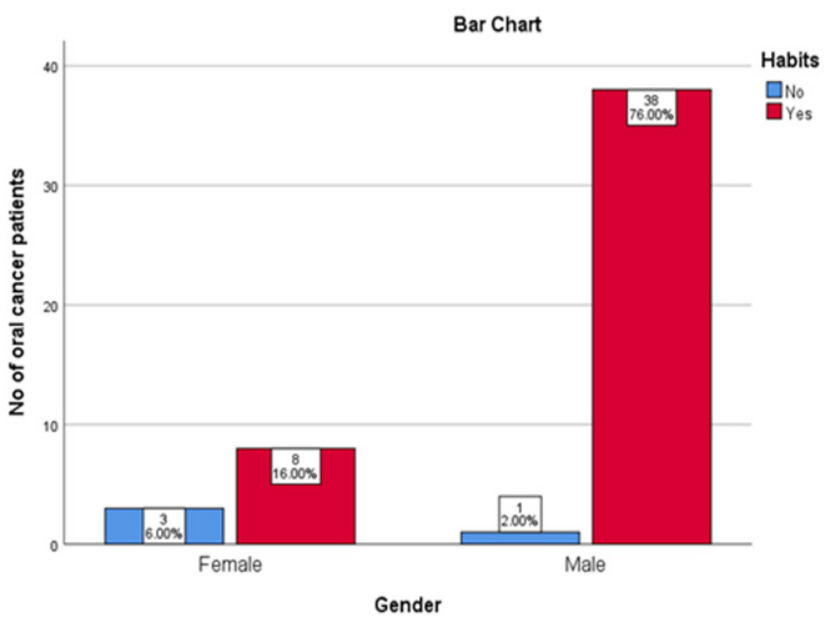

Figure 2: This is a bar graph showing the association between gender and the presence or absence of habits. The X-axis denotes the presence or absence of habits in males and females and $\mathrm{Y}$-axis denotes the number of oral cancer patients. The majority of oral cancer patients found to have adverse oral habits were males compared to females. A Chi-square test was done and the association was found to be statistically significant. Pearson's Chi-square value: 7.117 , df: 1, p-value: $0.008(<0.05)$, denoting there is a significant association between gender and the presence of habits. 
Oral cancer prevalence is high in developing countries and is the most common cancer in India. Oral cancer is observed as a multifactorial disease in which environmental, genetic, and epigenetic factors play a major role. Oral squamous cell carcinoma (OSCC) is rare in young patients and is most found in patients during the 6th and 7th decade of life, primarily occurring in males. Case-control studies have shown that smoking and/or alcohol is the major risk factor for oral cancer. In India, because of cultural, ethnic, geographic factors, and the popularity of addictive habits, the frequency of oral cancer is high.

Many studies state that the prevalence of habits in males is more than in females and because of this it has been observed that men face twice the risk of oral cancer when compared to females. ${ }^{10,11}$ In our study oral cancer in patients not having any habits was found to be $8 \%$. In a study conducted by Malovvala et al., it was found that $15 \%$ of the population had no oral habits which are in accordance with the present study. ${ }^{12}$ Similar results have been obtained by Shah et al. ${ }^{13}$ It has been observed that $2 \%$ of the population studied had mucosal changes without the presence of oral habits in a study conducted by Patil et al. ${ }^{14}$ A hospital-based 10-year retrospective study from Karnataka, reported that $25 \%$ of the patients diagnosed with oral cancer were habit-free, which is significantly more compared to the present study. ${ }^{15}$

The habits that were most commonly present in patients in our study include pan chewing, gutka, alcoholism, and smoking. It has been studied by Sankaranarayanan et al. that factors other than tobacco and alcohol are involved in the etiology of the oral tongue cancers and cancer in other intra-oral sites excluding buccal mucosa in young patients. ${ }^{16}$ It has been observed that mouthwash containing alcohol increased the risk of oral cancer in patients who neither smokes nor consumes alcohol, though the results were statistically not significant in a study conducted by Winn et al. ${ }^{17}$ The traditional risk factors of oral cancer have been extended to include other factors such as iron deficiency anemia, chronic candidiasis, and herpetic infections..$^{18}$ In a study done by Chang et al., it was found that HPV-associated oral cancer was significantly higher in patients without the presence of habits. ${ }^{19}$

Elevated fasting glucose level and estrogen deficiency have been observed to be a strong risk factor of oral cancer in females, especially in the cancer of the gingiva in a study conducted by Suba et al. ${ }^{20} \mathrm{~A}$ positive association was found between non-vegetarian diet, poor oral hygiene, poor dentition, and the development of oral cancer. ${ }^{21}$

Though the present study is in accordance with previous literature, the limitations faced in the study were smaller sample sizes and the results cannot be extrapolated to a larger population because of geographical limitations.

\section{CONCLUSION}

Within the limitations of the study, it was found that the number of patients diagnosed with oral cancer without any habits was comparatively less than those with adverse habits. Future studies on various other etiologies causing oral cancer and the etiopathogenesis should be studied, which will aid in the early diagnosis of oral cancer.

\section{ACKNOWLEDGEMENTS}

This study was supported by the Institution by providing insights and expertise that greatly assisted the study. We would also like to thank the reviewers of the article for the valuable insights provided by them.

Conflict of Interest: There was no conflict of interest.

Funding Information: The author confirmed that there is no funding support.

\section{REFERENCES}

1. Kumar M, Nanavati R, Modi TG, Dobariya C. Oral cancer: Etiology and risk factors: A review. J Cancer Res Ther 2016 Apr;12(2):458-63.

2. Wanebo HJ, Jun MY, Strong EW, Oettgen H. T-cell deficiency in patients with squamous cell cancer of the head and neck. Am J Surg 1975 Oct;130(4):445-51.

3. Kumari TV, Vasudevan DM, Ankathil R, Ramani P, Vijayakumar T. Demonstration of HSV-1 antigen in patients with oral cancer by immunofluorescence and immunoperoxidase techniques. Exp Pathol 1987; 3(75):1987;86.

4. Jenkins VK, Ray P, Ellis HN, Griffiths CM, Perry RR, Olson $\mathrm{MH}$. Lymphocyte response in patients with head and neck cancer: effect of clinical stage and radiotherapy. Arch Otolaryngol 1976 Oct;102(10):596-600.

5. Copper MP, Jovanovic A, Nauta JJ, Braakhuis BJ, de Vries N, van der Waal I, et al. Role of genetic factors in the etiology of squamous cell carcinoma of the head and neck. Arch Otolaryngol Head Neck Surg 1995 Feb;121(2):157-60.

6. Hernández G, Arriba L, Jiménez C, Bagán JV, Rivera B, Lucas $\mathrm{M}$, et al. Rapid progression from oral leukoplakia to carcinoma in an immunosuppressed liver transplant recipient. Oral Oncol 2003 Jan;39(1):87-90.

7. Hashibe M, Mathew B, Kuruvilla B, Thomas G, Sankaranarayanan R, Parkin DM, et al. Chewing tobacco, alcohol, and the risk of erythroplakia. Cancer Epidemiol Biomarkers Prev 2000 Jul;9(7):639-45.

8. James PD, Ellis IO. Malignant epithelial tumours associated with autoimmune sialadenitis. J Clin Pathol 1986;39,497-502.

9. Sankaranarayanan R, Mathew B, Varghese C, Sudhakaran PR, Menon V, Jayadeep A, et al. Chemoprevention of oral leukoplakia with vitamin A and beta carotene: an assessment. Oral Oncol 1997 Jul;33(4):231-6.

10. Varshitha A. Prevalence of oral cancer in India. Res J Pharm Biol Chem Sci 2015;7(10):845.

11. Patil PB, Bathi R, Chaudhari S. Prevalence of oral mucosal lesions in dental patients with tobacco smoking, chewing, and mixed habits: A cross-sectional study in South India. J Family Community Med 2013 May;20(2):130-5. 
12. Malaovalla AM, Silverman S, Mani NJ, Bilimoria KF, Smith LW. Oral cancer in 57,518 industrial workers of Gujarat, India: a prevalence and followup study. Cancer 1976 Apr;37(4):1882-6.

13. Shah S, Parikh N, Ayre D, Patel H, Sutariya R, Rakesh PS, et al. Prevalence of oral squamous cell carcinoma in South Gujarat population. Int J Prev Clin Dent Res 2019;6(2):42.

14. Aruna DS, Prasad KVV, Shavi GR, Ariga J, Rajesh G, Krishna M. Retrospective study on risk habits among oral cancer patients in Karnataka Cancer Therapy and Research Institute, Hubli, India. Asian Pac J Cancer Prev 2011;12(6):1561-6.

15. Mehta FS, Gupta PC, Daftary DK, Pindborg JJ, Choksi SK. An epidemiologic study of oral cancer and precancerous conditions among 101,761 villagers in Maharashtra, India. Int J Cancer 1972 Jul 15;10(1):134-41.

16. Sankaranarayanan R, Mohideen MN, Nair MK, Padmanabhan TK. Aetiology of oral cancer in patients less than or equal to 30 years of age. Br J Cancer 1989 Mar;59(3):439-40.
17. Winn DM, Diehl SR, Brown LM, Harty LC, Bravo-Otero E, Fraumeni JF Jr, et al. Mouthwash in the etiology of oral cancer in Puerto Rico. Cancer Causes Control 2001 Jun;12(5):419-29.

18. Binnie WH, Rankin KV, Mackenzie IC. Etiology of oral squamous cell carcinoma. J Oral Pathol 1983 Feb;12(1):11-29.

19. Chang JYF, Lin MC, Chiang CP. High-Risk Human Papillomaviruses May Have an Important Role in Non-Oral Habits-Associated Oral Squamous Cell Carcinomas in Taiwan. Am J Clin Pathol 2003 Dec;120(6):909-16.

20. Suba Z. Gender-related hormonal risk factors for oral cancer. Pathol Oncol Res 2007 Oct 7;13(3):195-202.

21. Subapriya R, Thangavelu A, Mathavan B, Ramachandran CR, Nagini S. Assessment of risk factors for oral squamous cell carcinoma in Chidambaram, Southern India: a case-control study. Eur J Cancer Prev 2007 Jun;16(3):251. 